\title{
Arthur Reis: da relação com os intelectuais amazonenses à sua colocação nos Institutos Históricos (1930-1940)
}

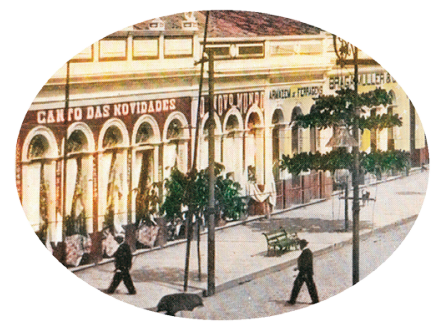

Lademe Correia de Sousa*

\section{Resumo}

Arthur Cezar Ferreira Reis publicou sua primeira obra, História do Amazonas, em 1931. E na década de 1940 já recebia os louvores dos intelectuais de Manaus pela produção historiográfica que constava no seu currículo. O artigo aborda, a partir das correspondências recebidas por Arthur Reis, a importância que adquiriu entre os intelectuais amazonenses e sua relação com os Institutos Históricos do Brasil.

Palavras-chave: História intelectual; instituto geográfico; histórico do Amazonas.

\begin{abstract}
Arthur Cezar Ferreira Reis published his first work, História do Amazonas, in 1931. And in the decade of 1940 it already received the intellectuals' from Manaus praises for the production in history that consisted in his curriculum. The article approaches, starting from the correspondences received by Arthur Reis, the importance that acquired between the intellectuals from Manaus and his relationship with the Historical Institutes of Brazil.
\end{abstract}

\footnotetext{
* Mestre em História pela Universidade Federal do Amazonas, professora substituta na mesma instituição. Este trabalho faz parte da dissertação de Mestrado em História intitulada Arthur Reis e a História do Amazonas: um início em grande estilo, financiado pela FAPEAM. E-mail: lademe98@hotmail.com
} 
Keywords: Intellectual history; geographical and historical; institute of Amazon.

\section{Introdução}

Arthur Reis, filho do jornalista Vicente Torres da Silva Reis e de Emília Ferreira da Silva Reis, nasceu em Manaus em 8 de janeiro de 1906, cresceu e se educou na capital da borracha durante seu período de crise, de onde se mudou para Belém em 1939 e depois para o Rio de Janeiro em 1945, construindo uma carreira que o consolidaria como especialista em assuntos amazônicos.

Membro do Instituto Geográfico e Histórico do Amazonas desde o início de sua juventude e redator da Revista Amazonense em 1923, dirigida por Álvaro Maia, Arthur Reis já dava mostra de sua ligação com a escrita que perdurou por toda sua vida. Entre os anos de 1928 e 1938, ocupou funções no magistério, exercido no Colégio Dom Bosco, lecionando História do Brasil, História da Civilização e História do Brasil na Escola Sólon de Lucena e Economia Política e Ciências das Finanças na Faculdade de Direito do Amazonas, entre outras. Foi redator do Jornal do Commercio, Diretor da Instrução Pública no governo de Álvaro Maia e Fiscal de Seguros da Primeira Circunscrição vinculado ao Ministério do Trabalho, Indústria e Comércio.

Elencamos apenas suas atribuições realizadas ainda em Manaus, por estarmos nos referindo, particularmente, à fase inicial de sua carreira. Carreira que, aliás, parece ter sido desejada desde muito cedo por seus pais. Ao menos é o que indica a seção de aniversariantes do Jornal do Commercio de propriedade de Vicente Torres, seu pai, que oportunamente na passagem do aniversário do filho, que completava catorze anos, em um texto quase profético, tendo em vista que previa uma carreira de sucesso para o tão jovem Arthur Reis, já o apresentava, através dos funcionários do jornal, como um grande prodígio:

Um acontecimento auspicioso faz vibrar de íntimo regozijo o lar do nosso diretor Dr. Vicente Reis e de seu idolatrado filho Arthur Cézar Ferreira Reis que entra no décimo quarto aniversário de sua existência. Jovem ainda trilhando a estrada ampla e luminosa de uma vida toda cheias de atrativos e expansões suaves, Artbur Reis é uma promessa que se revela, pois alia a sua exemplar conduta, um espírito inteligente 
e vivo, uma alma cheia de aspirações que só propendem para o esposamento de ideias nobres e elevadas.

As congratulações prosseguiram, dando a medida das expectativas com as quais o jovem era apresentado à sociedade local:

A sua maior preocupação é o estudo. No doce aconchego do lar, como no Ginásio Amazonense, onde cursa com brilhantismo, o terceiro ano de Ciências e Letras, jamais descurou de sua educação moral e espiritual, manuseando sempre com prazer os seus livros e ouvindo com desvelo as lições de seus mestres. Segue assim, um belo exemplo de virtude e civismo, tomando como lema a frase de Raul Pompeia: feliz é a alma que tenta, entre as florescências da juventude, descortinar o panorama imenso do futuro. É, pois, um jovem que orgulha os seus pais e o berço onde nasceu, iniciando os seus passos na arena espinhosa da vida, sob os influxos de muita esperança. Merecidas, portanto, serão as provas de afeto que receber nesse dia, de seus amiguinhos e admiradores, que são em grande número. (Jornal do Commercio, 8 de janeiro de 1920).

Arthur Reis era, portanto, apresentado, apesar da pouca idade, como uma promessa propensa ao cultivo de ideias nobres e elevadas, um belo exemplo de virtude e civismo que já possuía não poucos admiradores. Essa extensa nota sobre o aniversário de Arthur Reis fez parte da seção do jornal intitulada "Manaus Social", que anunciava somente os nomes dos aniversariantes do dia, entretanto, as figuras de relevo no cenário local recebiam espaço maior com direito a fotografia, como no seu caso.

Arthur Reis realmente preparação desde muito cedo, para construir uma sólida carreira intelectual. Aos vinte e cinco anos de idade publicou sua primeira obra, História do Amazonas, que tinha, entre outros objetivos, o de servir como modelo educativo à nova geração amazonense: "À geração nova de minha terra, para educar-se no exemplo dos homens que passaram e ter forças a fim de batalhar pelo Amazonas, que começa a redimir-se ao civismo de Álvaro Maia" (REIS, 1998: 13). ${ }^{1}$ Portanto, seu primeiro livro tinha um caráter claramente pedagógico, que visava instruir a juventude amazonense. 
Pelo que indicam as missivas recebidas por Arthur Reis, sua missão de ensinar aos moços amazonenses foi cumprida, em parte, já na década de 1940. Por meio das cartas, pode ser verificado o nível de influência que exercia sobre seus conterrâneos. Foi um intelectual manauense que buscou seu espaço e, ainda, muito jovem saiu de Manaus rumo a Belém, trocando uma capital em situação intelectual não tão privilegiada por outra, à época, vista como mais promissora. Belém simbolizava o primeiro passo para quem queria se deslocar rumo a um "novo mundo", pois servia como ponto de partida para os que queriam alçar voos mais altos, que levariam ao grande centro Sul/Sudeste. Um conjunto de cartas recebidas por Arthur Reis quando morava em Belém demonstra bem o que temos afirmado. Acerca da importância de Belém na carreira dos que queriam galgar melhores postos, escreveu Moacyr Dantas a Arthur Reis em 1941:

(...) Estimo saber que há possibilidade na minha ida até ahi, por conta da Prefeitura de Belém, para passar algum tempo fazendo estudos nos arquivos paraenses. (...) O essencialé sabir daqui com a garantia de um mez: O resto virá depois. (...) Peço-lhe também todo o seu prestígio.(...) Calcule a dor de cabeça dessa gente daqui, caso eu saia a convite do Prefeito de Belém! Imagine as caras... (DANTAS, 1941/ACPBAR). ${ }^{2}$

O primeiro e mais importante passo era sair de Manaus, símbolo de atraso cultural e intelectual. O sucesso viria consequentemente, com os contatos feitos em Belém, possibilitando maiores realizações nos grandes centros, sonho de grande parte dos estudiosos amazonenses:

Creio que Waldir já deve ter passado por aí. Este pode dizer-se que triunfou. Levado por seu esforço e trabalho, conseguiu atingir à meta de seus sonhos. Irá aos Estados Unidos sorver o supra-sumo da ciência que professa. E voltará, naturalmente, com uma nova mentalidade das coisas, sem a estreiteza de ambiente e de clima que vivemos e sem a involução que sofremos, principalmente na nossa terra natal. Infelizmente a verdade é dura e crua. Já que não o podemos acompanhar, resta-nos, a satisfação espiritual de vê-lo sair de um vale e meter-se num vastíssimo oceano, onde tudo é grande e belo. Onde não há limites 
na mentalidade, porque essa acompanhou as fronteiras extensas do desenvolvimento econômico e intelectual. Acompanhou de perto as fronteiras naturais que tomaram contato com outros povos. Ele haverá de elevar o nome de nosso Estado à altura que merece, embora este não tenha culpa de ser mal-orientado. O Amazonas é sempre o Estado sofredor e mais tristes são ainda os seus filhos, que são comparados às aves de arribação, nunca estão bem onde nascem - não podem de forma alguma se sujeitar ao mimetismo, porque aqui nada valem ou valem menos do que os estranhos. Para que possa progredir é necessário ir-se do torrão natal. Eis porque Waldir ganhou 100\% de vantagem e também porque todos nós ambicionamos sair daqui, mesmo até para outros Estados, contando que não vegetemos mais com os outros. E também porque o senhor triunfou aí e lá fora. E agora granjeou muitíssimo mais do que se aqui estivesse (VIEIRALVES, 1943/ACPBAR).

Arthur Reis havia conquistado um passo para a tão sonhada escalada rumo a outros centros; de Belém recebeu provas da admiração dos amigos amazonenses. Moacyr Dantas demonstrou, por meio das cartas, a medida da importância do grande historiador amazonense. Mencionando, em carta ainda de 1939, sobre o livro que estava escrevendo, pediu a Reis que escrevesse seu prefácio:

E o prefácio? Como vai? Nem o Dr. Álvaro Maia, nem o Jorge Andrade, nenhum leu os originais, pois somente quero dar-lhes depois de encadernados, juntamente com o prefácio. Isso é apenas um desejo de mostrar que minha obra recebeu o aplauso do mestre de estudos amazônicos. Nada mais (DANTAS, 1939/ACPBAR).

Dantas dispensava ao "Dr. Arthur Reis" um tratamento respeitoso e formal, ao mesmo tempo em que expressava um nível íntimo de amizade entre os dois; amizade baseada na admiração pelo historiador que, desde muito cedo, já figurava como grande exemplo a ser seguido, como expressou seu discípulo: "Dr. Arthur Reis, (...) Estou resolvido a seguir-lhe os passos, senão publicando obras, ao menos escrevendo-as para eu próprio ler” (DANTAS, 
1940/ACPBAR).

André Araújo também expressou sua admiração por Arthur Reis, elegendo sua obra como grande contribuição aos amazonenses:

Recebi o seu magnífico livro "A política de Portugal no vale amazônico", que muitíssimo lhe agradeço. (...) li-o todo de um fôlego só, pois o que você escreve tem o dom de atrair o espírito daqueles que sabem apreciar a erudição. (...) Pretendo escrever breve um trabalho de apreciação ao seu livro, que bem merece o acolhimento que tem tido nas rodas intelectuais do Paiz. Essa obra veio afirmar mais uma vez as suas grandes qualidade de historiador e sociólogo. (...) O Amazonas, ou melhor, o Brasil, já deve ao seu talento uma das maiores contribuições em prol das futuras gerações (ARAÚJO, 1940/ACPBAR).

A Politica de Portugal no Vale Amaz̧ônico era o livro do momento, publicação recente com a qual presenteava os amigos, como fez com a História do Amazonas (SOUSA, 2009), ${ }^{3}$ mas tendo o autor muito mais renome e reconhecimento nas rodas intelectuais do País. Antonio Maia, prefeito de Manaus em 1940, expressa sua opinião acerca das obras do autor que se tornara motivo de orgulho para os amazonenses:

Prezado e ilustre amigo Arthur Cezar, (...) Tenho grande satisfação em acusar recebido o exemplar da nova e magnífica obra de sua autoria intitulada "A política de Portugal no vale amazônico" (...) Suas obras representam para o Amazonas um verdadeiro patrimônio históricocultural, já pela realidade descritiva dos seus entrechos, já pela escolha feliz dos seus temas (MAIA, 1940/ACPBAR).

Moacyr Dantas continuou asseverando sobre a importância que o "mestre dos moços", Dr. Arthur Reis tinha, junto à intelectualidade, e de como suas opiniões possuíam grande valor no meio intelectual amazonense. Reis o orientava em relação aos trabalhos que estava escrevendo, e este, querendo se mostrar digno dessa orientação, interpelou e desafiou o mestre:

Recebi sua carta, onde me falava a respeito do estudo que escrevi sobre o problema do índio na Amazônia. 
Diz o senhor que entre o regime de colonização inglês e espanhol com o português, há grande diferença. Concordo. Apesar disso, espero seus ensinamentos, no artigo que vai escrever, para então me convencer de que havia bumanidade na colonização do homem português. Disse, no meu artigo, que a política da Corte era toda de proteção e de amparo ao índio. As leis que a metrópole nos mandava, todas elas, eram de caráter benigno. Não neguei isso. Neguei apenas que elas fossem adotadas aqui. A culpa da desumanidade existente, portanto, não cabe a administração, mas somente ao colono em si. Não acha que tenho alguma razão? (DANTAS, 1940/ ACPBAR).

Moacyr Dantas queria ser convencido por Arthur Reis, de que havia humanidade na colonização portuguesa, dando a entender que havia recebido deste, através de carta, tal afirmativa. Isso só confirma a defesa que Arthur Reis fez da colonização, o que, aliás, salta aos olhos na leitura da sua obra pelo leitor mais desavisado. Nesse sentido, podemos relacioná-lo a Francisco Adolfo Varnhagem. ${ }^{4}$ José Carlos Reis trabalhou com clareza essa questão na História Geral do Brasil de Varnhagem, demonstrando que "o olhar de Varnhagem sobre a história do Brasil é... o olhar do colonizador português” (REIS, 2007, p. 33). A colonização foi vista por este "como bem-sucedida, trouxera a civilização européia, a religião cristã e tornara produtiva uma região abandonada e desconhecida. Portugal integrou o Brasil na rota da 'grande história' (REIS, 2007, P.32). Nessa questão, a diferença entre ambos, era apenas que Arthur Reis em vários pontos reconheceu as atrocidades cometidas pelos portugueses, mas as justificou, sendo, desse modo, conivente; enquanto que Varnhagem defendeu com mais contundência, tendendo mesmo, a não reconhecer a violência praticada, em muitos momentos, durante o processo de colonização. Conforme José Carlos Reis, Varnhagem defendeu,

como sempre o colonizador: eles não matavam e escravizavam os índios! Não sejamos tão injustos com os nossos antepassados! Eles não podem se defender! Se houve excessos, foram punidos. Os donatários se comportaram bem com os indígenas! Eles procuraram cooptá-los, defendê-los, tutelá-los, cristianiza-los. A força só foi usada contra os mais ferozes. O tipo índio, na verdade, ele afirma, 
desapareceu mais em virtude de cruzamentos sucessivos do que do verdadeiro e cruel extermínio (REIS, 2007, p. 40-41).

Mas, retornando às cartas recebidas por Arthur Reis de Moacyr Dantas. Nessa relação de embate produtivo, em 30 de abril de 1941, Dantas suplicou pelo apoio de Reis ao seu trabalho e se propôs a retribuí-lo publicando críticas aos seus livros Lobo d'Almada e D. Romualdo de Sousa Coelho. Essa carta também expressa possíveis rejeições dos governantes e da imprensa às realizações de Reis, que merecem ser investigadas em momento apropriado.

Dr. Arthur Reis (...) Sei que o Mário Ipiranga e o Aderson de Menezes vão publicar criticas, muito favoráveis a respeito da minha tese. Mandarei ambas, para que o senhor veja como está sendo encarada, pelos moços daqui, uma vitória de moço. Não esqueça de que a sua opinião escrita sobe até nós todos como uma afirmação única. Peço, por isso, sua opinião. (...) Já deve ter sabido de que fiz aproximação com o Abelardo Conduru e em um almoço íntimo, em casa dele, aclareei a situação em que vivemos no Amazonas. Interessante a admiração que ele sentiu ao saber que "o mestre dos moços" (o Dr. Arthur) era visto com pouco apreço pelos governantes da terra e até por gente de imprensa. (...) Logo que receba o seu livro publicarei algo. Não se espante com o que escreverei. O seu "Lobo d'Almada" e o "D. Romualdo de Sousa Coelho" serão retratados. Mas retratados à minha maneira. O Mário Ipiranga também escreverá a respeito (DANTAS, 1941/ ACPBAR).

Mas é de 1943 a carta que dá maior ênfase à missão de orientador de Arthur Reis:

Creio que estou em grande falta com o ilustre professor. De vez enquanto tenho sabido de notícias agradáveis acerca de sua personalidade e procurado ter contacto com a sua família aqui (...). Sentimos a sua falta, quando pela vez primeira saiu daqui. Era o nosso mentor intelectual. Não somente nosso como da mocidade amazonense. Esta foi que mais sofreu com a sua falta. Hoje não tem aquela orientação nos traçados de estudo com a que sempre lhe 
acudia nos momentos mais precisos. Acha-se atualmente desunificada, dispersada, melhor. Talvez hoje já tivéssemos grupos bastante aproveitáveis, centros de estudos e especializações. Justamente é a nossa grande falta. Não possuímos nem grupos, nem centros de estudos e menos ainda especializações. Por quê? Por falta de um orientador, de um mentor da mocidade. Esta era a sua grande função aqui em Manaus. Cabia-lhe a missão árdua, mas dignificante porque seriam reflexos de sua personalidade... $\mathrm{E}$ nos vimos forçados a ficar sós, sem a sua assistência e sem a sua aquilatada orientação” (VIEIRALVES, 1941/ACPBAR).

Em 1944, Geraldo Pinheiro também reverenciou o mestre:

Caro prof. Arthur Reis (...) Sua carta, datada de Belém, deu-me a satisfação esperada, pois é sempre com alegria que noto o mesmo entusiasmo e amor, da parte do mestre, pelos assuntos de nossa terra. Grato pela leitura dos meus trabalhos e o oferecimento de sua orientação, para minha pessoa, desde os bancos de escola, tão valiosa e indispensável” (PINHEIRO, 1944/ACPBAR).

Desse modo, a proposição de Arthur Reis foi em grande parte cumprida. Através do prestígio que alcançou com a produção incansável de trabalhos historiográficos conseguiu influenciar parte dos moços amazonenses, proposta da sua História do Amazonas. As cartas recebidas dos amigos de Manaus, de modo geral, davam notícias do meio intelectual local, deixando latente a sensação de abandono pela qual passava a região em termos intelectuais. Arthur Reis representava o "sucesso", na medida em que estava conseguido despontar nos círculos intelectuais dos grandes centros do País.

Num conjunto de cartas recebidas entre os anos de 1944 e 1949, fica notório o que temos afirmado. Manaus ainda era, na visão de seus intelectuais, um ambiente provinciano e a narrativa contida nas cartas que expressavam com pesar a situação do local, tinha o objetivo de compartilhar a situação de penúria pela qual passava a cidade, mas também visava receber alguma ajuda do "mentor intelectual". Afinal, este estava em contato com pessoas que representavam o ápice da produção intelectual do país, e os manauenses que se 
correspondiam com Arthur Reis pareciam ávidos em participar desse círculo, como demonstra essa carta de Walter Vieiralves:

Continuo a ser um fervoroso admirador de seus trabalhos e de seu valor pessoal. Seu nome, aqui em Manaus, ainda é de vez em quando relembrado por antigos discípulos, amigos e por todos os que veem, indiscutivelmente o seu valor. Parece, que, quanto mais se distancia, mais se aproxima o seu contato, a falta que faz na orientação das gerações novas e no aprumo dos futuros destinos de nossa triste terra. Faz anos que o professor daqui saiu, amargurado pelo meio sórdido, ingrato e fartamente hipócrita. Também outros já tomaram a mesma resolução. Agora, é minha vez. Saturado das decepções administrativas que diariamente presenciamos, do retrocesso da civilização e do ambiente extremamente oposto à nossa mentalidade, é que resolvi ir com minha pequena família residir em São Paulo. Creio que o prezado amigo é conhecedor do meio e do ambiente que ora temos atravessado aqui. Nada se faz, nada se constrói, nada se produz. Tudo se vê. Parece a lei de Lavousier ao contrário. E assim, com os mesmos propósitos seus e dos que se seguiram, outros virão atrás de mim, decepcionados com os homens daqui. O Amazonas sempre é o Estado que fica no extremo. Até na interpretação da mentalidade sempre é o último a compreender o progresso. Em outros Estados a mentalidade nova está em franco desenvolvimento e trabalho. Aqui, ainda continuam os partidarismos improdutivos e que tem por finalidade tornar o Estado do Amazonas sempre na retaguarda da retaguarda. Vejo-me, como filho daqui, a decidir o dilema irrefragável, emigrado do Estado ou sucumbir. Eu vou optar pelo audacioso de sair daqui, onde tudo é farsa e por este motivo é que nada temos e nada somos. Parece incrível esta realidade que se anuncia pelo lado oposto. Mas, porque temos uma política de tapeação, de embromação é que permanecemos sempre iludidos e nos iludindo a nós mesmos. Eis porque prezado professor, dentro em breve, deixarei a nossa terra na esperança de me divorciar completamente dela, de me desligar de todos os seus vínculos, para não mais participar dessa inércia material e moral que assola os nossos 
responsáveis pelo retrocesso do Amazonas (VIEIRALVES, 1944/ACPBAR).

A expressão "de vez em quando", usada pelo autor da carta, para as lembranças que os manauenses tinham de Arthur Reis, não diminui absolutamente, o valor que o mesmo tinha para sua região. O próprio autor da carta menciona a falta que Arthur Reis fazia na orientação às novas gerações. Mas, o que realmente queremos destacar dessas relações são as descrições de uma Manaus que estava pedindo socorro, como sugere essa missiva de Geraldo Pinheiro:

Felizmente tenho a registrar para o mestre e amigo que o ambiente de Manaus está se modificando a contento. Como deveis saber, eu, Nunes, André, Ypiranga e outros fundamos há alguns meses o Instituto de Etnologia e Sociologia do Amazonas, reunindo um grupo de elementos mobilizáveis visando, exclusivamente, a terra e os seus problemas culturais. O ideal seria a criação de um centro de estudos amazônicos para abranger toda a preocupação de estudar o que é nosso. Estamos em pleno movimento e tudo leva a crer que venceremos a apatia do meio e a indiferença dos responsáveis pelo destino de nossa terra. Esperamos contar com vossa preciosa orientação no desenvolvimento de nossas pesquisas (PINHEIRO, 1944/ACPBAR).

Geraldo Pinheiro apresentou a criação de um novo Instituto, como paliativo à situação de "apatia" pela qual passava a cidade. Com outras palavras, mas, expressando a mesma situação, Djalma Batista reiterou:

O Amazonas, que não o compreendeu, permitiu-lhe ao menos isto: que, com a sua (digamos a palavra certa) expulsão, lhe fossem abertas novas perspectivas aos labores intelectuais, e muito mais ampla projeção perante o Brasil. O País todo está lhe concedendo aquilo que a provincia mesquinha lhe negou. Abstraindo o travo inelutável da mágoa que deve pungi-lo, por sem dúvida, convenhamos que a vantagem foi sua, foi do Brasil e foi também do Amazonas, onde não havia clima espiritual para a ampliação, que agora se 
corrobora, dos horizontes de sua vida. (...) Meus parabéns, pois, meu abraço fraterno e amigo, de congratulações pelas suas merecidas vitórias. Esteja certo de que eu e muitos moços, que lhe somos gratos e lhe conhecemos o quilate da inteligência, o acompanhamos daqui, na sua escalada ascensional, com o melhor do nosso carinho e da nossa simpatia (BATISTA, 1947/ACPBAR).

Num misto de admiração por Arthur Reis, descontentamento com a situação local e pedido de ajuda intelectual, as cartas indicam a importância do manauense que havia dado um passo em busca de alçar maiores voos:

Recebi a sua amável notícia de haver a minha tese sido aprovada com "grandes louvores" aí no Congresso. Mas os grandes louvores não serão porventura bondade tua? Sei que devo agradecer a sua imediata preocupação, pois de outro modo não creio que ela tivesse sido tão louvada. Mas como quer que seja, foi para mim uma surpresa agradável a tua noticia telegráfica. Espero que tenha gostado da representação amazonense no Congresso. Ao menos não se diga que ficamos no esquecimento, e você, meu nobre amigo, não se esqueça de para o futuro procurar levar-me pela mão até essa gente, que nós desconhecemos como provincianos que somos (MONTEIRO, 1949/ACPBAR).

De forma mais explícita, Mário Ipiranga, na carta citada acima, contou com o amigo, para sua inclusão, como era comum no interior da "barganha saudável" que ocorria de um modo geral, entre os intelectuais do País. Anísio Jobim também contava com Arthur nesse mesmo sentido:

Respondo sua última carta que me deu muito prazer. E creia, estou admirado da sua invejável capacidade de trabalho, em se tratando de coisas difíceis, e em que entra em grande cópia a pesquisa bem dirigida. (...) Fico-lhe muito obrigado por tudo. Desejo ingressar como sócio correspondente do Instituto Histórico Brasileiro. Você será o braço que me guiará a essa altura (JOBIM, 1949/ACPBAR). 
Em suma, esse conjunto de cartas exposto, demonstra ao menos três situações: $1^{\circ}$ ) Os méritos colhidos por Arthur Reis entre os intelectuais manauenses, cumprindo o objetivo citado na História do Amazonas de educar a nova geração de sua terra "no exemplo dos homens que passaram" (REIS, 1989, p.13); $2^{\circ}$ ) As queixas feitas por seus amigos em relação à situação da intelectualidade local, inclusive retratando-a como província, e sua população como sendo de provincianos, termos pejorativos usados respectivamente por Djalma Batista e Mário Ipiranga, denotando o lugar de inferioridade ocupado pela cidade em relação aos grandes centros de produção literária ; $3^{\circ}$ ) E consequentemente essas queixas assumiam a função de um pedido de ajuda a um autor da "terra" que, pelo trabalho realizado e pelo papel que já ocupava junto à intelectualidade brasileira, representava um possível e provável apoio aos seus pares.

Arthur Reis foi incumbido e assumiu o papel de "padrinho" da intelectualidade manauara. Sendo ao longo do tempo considerado pelos seus amigos e intelectuais manauenses, como exemplo de profissional e refúgio à falta de estrutura em termos de incentivo à pesquisa pela qual passava a cidade. O padre Raimundo Nonato Pinheiro quando tratou dos "Aspectos evolutivos do IGHA”, escrito em 1967, retratou bem essa situação:

Arthur Cezar Ferreira Reis marca uma fulgurante moldura nessa casa, que lhe dedicou um salão e lhe apôs o retrato no dia da sua solene reinauguração. Seu amor ao Instituto vem de longa data. E sem sua passagem pelo governo do Estado, tão benéfica ao progresso cultural do Amazonas não teria sido possivel a recuperação desta Casa, e mais do que sua recuperação, sua prodigiosa opulentação" (PINHEIRO, 1967).

A despeito do tom de lisonja contida nessas declarações, as mesmas denotam a importância que Arthur Reis continuou a ter para os intelectuais do Amazonas, pois em 1967, muitos anos depois de sua primeira publicação e agora com o peso de ter sido governador do Estado, recebia, ainda mais, os louvores pela atuação junto aos intelectuais locais. O Boletim do IGHA de $\mathrm{n}^{\circ}$ 03 expõe a situação de abandono da Instituição e a falta de investimento das autoridades, realidade melhorada quando da passagem de Arthur Reis pelo Governo: 
Era o Governo Revolucionário do professor Arthur Cezar Ferreira Reis, que assumia as rédeas do Estado, era o secretário perpétuo do Instituto Geografico e Histórico do Amazonas que estava no poder e numa visita que fez, a nosso pedido, a "Casa da Memória Amazonense", num domingo, acompanhado da esposa e que constatou a miséria e sua decepção foi incontida, sentiu também a revolta e vendo a necessidade por que passávamos deu-nos uma ajuda de dois milhões de cruzeiros velhos, com a qual, num alento de satisfação, pudemos evitar, em parte, a queda desastrada de nosso rico Salão Nobre... (BOLETIM DO IGHA, 1967).

Trinta e seis anos depois de sua primeira publicação, Arthur Reis ainda com mais força continuava a ser o "mestre dos moços", certamente que com alguns desafetos, ${ }^{5}$ porém, mantendo sua posição de destaque iniciada na década de 1930 com a edição de sua primeira obra. Na década de 1940, encontramolo, visto por meio das cartas recebidas, como grande historiador a oferecer um auxílio aos colegas no campo das ideias. Em 1967, depois de ter passado pelo governo, foi reconhecido por poder contribuir também com a estrutura física da Instituição que representava o centro do conhecimento geográfico e histórico da região. Aliás, essa relação de Arthur Reis com o IGHA, e com os vários institutos históricos do País já existia antes dele publicar a História do Amazonas (1931), como veremos a seguir.

Os institutos históricos fundados em vários Estados brasileiros, em geral seguiram o mesmo propósito do pioneiro Instituto Histórico Geográfico Brasileiro (IHGB), com fundação em 1838. Foi esse o caso do Instituto Geográfico e Histórico do Amazonas (IGHA), inaugurado em março de 1917 com seus objetivos voltados ao:

estudo, discussão, investigação, desenvolvimento e vulgarização da Geografia, da História e das ciências a elas conexas... reunindo, concatenando, publicando e arquivando documentos e trabalhos concernentes ao Brasil e especialmente ao Estado do Amazonas (COSTA, 1997, p. 188). 
Envolvidos por esses objetivos, certamente que os intelectuais associados ao IGHA buscavam inserção numa associação que respaldasse seus trabalhos, que os fizessem ser reconhecidos como pertencentes a um grupo seleto. Portanto, o Instituto era mais que "relicário das honrosas tradições amazonenses" (COSTA, 1997, p. 187); era reduto de pessoas que recebiam o "status" de a ele pertencer, validando as produções científicas e culturais dos seus sócios. O diploma de sócio do Instituto era quase como o passaporte que possibilitava o livre transitar de seus membros em outros círculos intelectuais fora do Estado. Isto é, pertencer a um, ou mais dos Institutos existentes no País facilitava as relações com a intelectualidade dos demais centros destinados à produção científica e cultural, ao menos é o que demonstra Mário França (Rio de Janeiro), em carta dirigida a Arthur Reis, datada de 22 de dezembro de 1933:

Consegui mais uma boa quantidade de livros sobre história e Geografia dos Estados em que passava, visitando ao mesmo tempo seus respectivos institutos históricos. Fazendo sempre valer a qualidade de sócio dos do Amazonas e Pará, era por toda a gente recebido com a maior gentileza e simpatia. (grifo meu) Estive dest'arte nos do Maranhão, onde me recebeu o Dr. Antonio Lopes, no do Ceará, no do Rio Grande do Norte, acompanhado do Luiz da Câmara Cascudo, no da Bahia (mas que colosso que realmente é, de fato o primeiro do Brasil) no de Alagoas, com Craveiro da Costa e no de Pernambuco com Mario Melo. O da Paraíba estava fechado e não houve meio de encontrar o secretario. Também obtive com as autoridades locais, que sempre visitava, mapas murais de quase todos os Estados. Quanto a livros devo lhe dizer que cheguei ao Rio com cinco caixotes e, um vasto embrulho deles (FRANÇA, 1933/ACPBAR).

E foi desse respaldo oferecido pelo IGHA, que Arthur Reis legitimamente se beneficiou, facilitando o seu reconhecimento nos grandes centros Rio-São Paulo. A primeira edição da sua História do Amaz̧onas traz na capa a comprovação da qualidade do livro, pois foi produzido por "Arthur Cezar Ferreira Reis, do Instituto Histórico e Geográfico do Amazonas", e esse era um dos selos de certificação de competência do autor. 
A ata de 21 de março de 1926, constante nos arquivos do IGHA, registra a reunião ordinária onde foram propostos e aprovados como sócios efetivos os nomes "dos Senhores Doutores Manuel Pais Barreto, Marcílio Dias, Arthur Reis, Paulo Sarmento, Roberval Pompílio Nogueira Castro" (LIVROS DE ATAS/IGHA, 1926). Portanto, Reis foi eleito aos vinte anos de idade, ainda em fase de conclusão do seu curso de Direito, num período em que acabava de ser instituído o novo corpo administrativo do Instituto, para os anos de 1926 a 1929, tendo como presidente reeleito Bernardo Ramos e como primeiro secretário Agnello Bittencourt. Nessa reunião de 21 de março, o "senhor presidente marcou às oito horas da noite de vinte e cinco do corrente para ter lugar a sessão plenária de posse dos novos eleitos" (LIVROS DE ATAS/ IGHA, 1926), propositalmente no dia em que o Instituto completaria nove anos de existência, tornando ainda mais memorável a solenidade de posse.

O próximo passo de Arthur Reis no Instituto foi ocupar o cargo administrativo de primeiro secretário em 1931, coincidência ou não, no ano de publicação da História do Amažnas. A eleição ocorreu na sessão extraordinária de Assembleia Geral, em 22 de março, convocada especificamente para fins de eleição de membros a cargos vagos. Assim:

O Senhor Presidente (Alfredo da Matta) mostrou a necessidade de ser o cargo de $1^{\circ}$ Secretário preenchido por sócio que aliasse zelo e dedicação a conhecimentos dos múltiplos ramos da atividade do Instituto. Autorizado pela Assembleia a indicar um nome, indicou o do sócio Dr. Arthur Cezar Ferreira Reis, que foi aclamado por unanimidade (LIVRO DE ATAS/IGHA, 1931).

Estando bem colocado no seu Instituto, e com um livro publicado, Arthur Reis seguiu os procurou ter aceitação e livre circulação entre os intelectuais de outros Institutos de pesquisa do País, muito auxiliado pelas correspondências trocadas com grandes nomes desses Institutos, que o subsidiavam na indicação do seu nome, numa relação de troca. Arthur Reis também fazia suas indicações para eleição de sócios correspondentes do IGHA. Como demonstra Luiz Câmara Cascudo, em carta de 1936: "Mandei todos os meus agradecimentos pela proposta ao Instituto e solicitei de você uns dois livros seus e me permiti apresentá-lo no nosso Instituto potiguar na próxima sessão" (CASCUDO, 
1937/ACPBAR). A reciprocidade dos amigos intelectuais lhes rendeu frutos, confirmado por outra carta de Câmara Cascudo em 1937:

Recebi o número da revista do Instituto Histórico do Amazonas assim como um oficio assinado por V. informando a aprovação do parecer que me aceita por sócio correspondente. Creio que V. já deve ter em mão comunicação idêntica a respeito de seu ingresso no Instituto daqui, desde 12 ou 13 de março p.p. (...) Muita alegria tive em poder incluí-lo no nosso Instituto e não foi menor honra saber-mo sócio do "seu" Instituto (CASCUDO, 1937/ ACPBAR).

Nessa mesma carta, Câmara Cascudo elogiou Arthur Reis por suas publicações nas Revistas do IHGB, de onde já era membro desde dezembro de 1936, quando recebeu de Max Fleuss, $1^{\circ}$ Secretário, o comunicado: "foi por unanimidade de votos aprovado o parecer da Comissão de Admissão de Sócios favorável á entrada de V. Exa para a classe dos membros correspondentes" (CASCUDO, 1937/ACPBAR).

A documentação não nos permite afirmar com precisão se a aprovação de Reis para o IHGB, foi realizada por indicação de Max Fleiuss, mas certamente teve sua influência e a de Afonso de Taunay que tinham pelo autor amazonense uma alta estima. Trocou com Taunay diversas correspondências. Nas recebidas por Reis, Taunay assinava como "afetuoso e grande amigo", e de Fleiuss recebia "um afetuoso abraço".

Foi a partir desse círculo de trocas que Reis passou também a fazer parte do Instituto de Estudos Genealógicos de São Paulo por indicação do secretário José Bueno de Oliveira Azevedo Filho, que diz em carta de 1935:

Consulto o prezado amigo se poderei propor-lhe o nome para membro correspondente do Instituto de Estudos Genealógicos... Tal distinção é puramente honorífica, não acarretando nenhuma obrigação. E nada mais é que uma homenagem que o "Instituto" presta a quem dela é merecedor, residindo fora da cidade de São Paulo... (AZEVEDO FILHO, 1935/ACPBAR).

Convite aceito, Reis foi eleito como membro correspondente em 
novembro de 1935. Mas, descuidado em retribuir o amigo, foi por ele cobrado em abril de 1936:

Como foi recebido aí meu trabalho folclórico? Ele seria suficiente para me aproximar (sob sua égide) do Instituto Histórico do Amazonas? Peço sua condescendência para um escritor tão modesto quão bem-intencionado... (AZEVEDO FILHO, 1936/ACPBAR).

José Bueno pede a interferência do amigo para fazer parte do IGHA, nessa saudável barganha intelectual, ao mesmo tempo em que reafirma a confiança que tem em Reis quando este indica alguns nomes para fazer parte do Instituto de Estudos Genealógicos: "A sua proposta do nome do Jorge Hurley já foi aceita e ele proclamado. (...) Subscrevi a proposta com muito gosto. Repito que todos os seus candidatos, o são meus também" (AZEVEDO FILHO, 1936/ACPBAR).

As correspondências recebidas por Arthur demonstram o intercâmbio comum entre os intelectuais da época, pois seus vínculos de amizade intermediavam a aceitação de novos sócios indicados pelos laços de respeito e admiração mútua pelos trabalhos realizados. E era uma prática comum a troca de notícias sobre a atuação dos institutos, pois cada um queria fazer conhecida a atuação do seu Instituto e, ainda compartilhar a falta de uma atuação mais enérgica.

Em viagem a Belém, Ambrosio Peres escreveu a Arthur Reis, lamentando a situação do Instituto Paraense:

O Instituto Histórico e Geográfico do Pará, funciona n'uma das dependências da Prefeitura Municipal. É muito acanhado. A biblioteca é inferior à nossa, tanto em número de exemplares como na organização. Possui elevado número de sócios. Mas de nada valem. Lá não aparecem. Está análogo ao do Amazonas, infelizmente (PERES, 1933/ ACPBAR).

Os institutos eram os santuários de preservação e criação científicas e foi inicialmente, com base nos seus pressupostos teórico-metodológicos que Arthur Reis desenvolveu seus primeiros trabalhos. 


\section{Notas}

1 A dissertação da qual se originou esse trabalho traz um capítulo intitulado Por uma história cívica que aborda a relação de Arthur Reis com Álvaro Maia e o intuito daquele em dar um tom pedagógico a sua obra.

${ }^{2}$ As referências assim utilizadas são partes do Acervo de Correspondências Passivas da Biblioteca Arthur Reis (ACPBAR), que ainda estão em processo de classificação e catalogação. A referência completa consta no final deste trabalho.

${ }^{3}$ Arthur Reis distribuiu sua primeira obra a muitos intelectuais brasileiros, dos quais recebeu cartas em agradecimento.

${ }^{4}$ Uma das influências recebidas por Arthur Reis foi a da história escrita por Varnhagem como demonstra o capítulo intitulado Arthur Reis: entre Varnhagem e Capistrano de Abren da dissertação que deu origem a este trabalho.

${ }^{5}$ Álvaro Maia, anos depois da proximidade que teve com Arthur Reis (demonstrado na dissertação que deu origem a esse trabalho), parece ter se tornado seu desafeto.

Referências

BRAGA, Robério dos Santos Pereira. Arthur Cezar Ferreira Reis. Manaus: Imprensa Universitária, s.d.

Boletim do IGHA. n. 3, 1967.

COSTA, Selda Vale da. Labirintos do saber: Nunes Pereira e as culturas amazônicas. Tese de Doutorado defendida na PUC de São Paulo, 1997.

PINHEIRO, Raimundo Nonato. Aspectos evolutivos do IGHA. In: Boletim do IGHA. Edição Comemorativa ao Cinquentenário de Fundação do Instituto, 1967.

REIS, Arthur Cezar Ferreira. História do Amazonas. Belo Horizonte: Itatiaia, 1998.

REIS, José Carlos. As Identidades do Brasil: de Varnhagen a FHC. Rio de Janeiro: Editora FGV, 2007.

SOUSA, Lademe Correia de. Arthur Reis e a História do Amazonas: um início em grande estilo. Dissertação de Mestrado defendida na Universidade Federal do Amazonas, 2009. 


\section{Fontes}

Livro de Atas de 1926 do Instituto Geográfico e Histórico do Amazonas, localizadas neste mesmo Instituto.

Livro de Atas. Ata da reunião realizada em 22 de março de 1931. In: Acervo do IGHA.

Jornal do Commercio, 8 de janeiro de 1920

Acervo de Correspondências Passivas da Biblioteca Arthur Reis (ACPBAR)

Carta de Ambrósio Peres. Belém, 23 de janeiro de 1933.

Carta de Mário França. Rio de Janeiro, 22 de dezembro de 1933.

Carta de José Bueno de Oliveira de Azevedo Filho. São Paulo, 29 de setembro de 1935.

Carta de José Bueno de Oliveira de Azevedo Filho. São Paulo em 27 de abril de 1936.

Carta de Luiz Câmara Cascudo. Natal, 28 de abril de 1937.

Carta de Moacyr Dantas. Manaus, 5 de março de 1939.

Carta de Moacyr Dantas de Manaus em 23 de abril de 1940.

Carta de André Araújo. Manaus, 8 de abril de 1940.

Carta de Antônio Maia. Manaus, 13 de fevereiro de 1940.

Carta de Moacyr Dantas. Manaus, 17 de junho de 1940.

Carta de Moacyr Dantas. Manaus, 30 de abril de 1941.

Carta de Moacyr Dantas. Manaus, 7 de maio de 1941.

Carta de Walter Vieralves. Manaus, 10 de fevereiro de 1941.

Carta de Walter Vieiralves. Manaus, 22 de setembro de 1943.

Carta de Geraldo Pinheiro. Manaus, 13 de setembro de 1944.

Carta de Walter Vieiralves. Manaus, 18 de janeiro de 1944. 
Carta de Geraldo Pinheiro. Manaus em 9 de agosto de 1944.

Carta recebida de Djalma Batista de Manaus em 25 de outubro de 1947.

Carta recebida de Mario Ipiranga Monteiro de Manaus em 11 de maio de 1949.

Carta recebida de Anísio Jobim de Manaus em 27 de fevereiro de 1949. 